\title{
On the Verbal Expression of Emotions: Language and Emotion Interplays
}

\author{
Ani Stepanyan \\ Yerevan State University
}

\begin{abstract}
In pre-historic times people used to communicate with each other through grunts, barks and roars. They gradually developed an elaborate set of sounds to express their emotions and convey their messages. Now it is the systematic use of language that differentiates human beings from animals. The interpersonal communication of emotional states is fundamental to everyday verbal interactions, and the way these emotions are expressed and understood is important in cross-cultural and interpersonal relationships. The verbal descriptions of emotional states can provide quite precise information about different forms of emotions.
\end{abstract}

Key words: emotion, verbal expression, non-verbal, communication, semantic metalanguage, universal, emotionology, schemata.

\section{Introduction}

It is well established that humans use a wide range of nonverbal and paralinguistic mechanisms to express emotions, including facial expression, gestures, posture, tone of voice, and the like. However, paralinguistic and nonverbal channels are insufficient to express the full range of human emotional experiences for several reasons. First, although nonverbal cues can indicate what general class of emotions a person is feeling, they typically do not provide detailed information about that person's emotional state. Secondly, many nonverbal behaviors are signs rather than intentional signals of emotional state; they have limited value in communicating about emotions one is not experiencing at the time of communication. For instance, by seeing that someone is crying, we might assume that he/she is sad; by the extent of sobbing we might even be able to infer the intensity of the sadness. But the tears in and off themselves provide no information about the particular experience of sadness (even happiness) and the cognitions that go along with the sadness (e.g., "I have no money" vs "I'm lonely") or the circumstances that lead up to the feeling of sadness (e.g., "I lost my job" vs "My dog just died"). Hence, we drive at the point that verbal descriptions of emotional states can provide quite precise information about the specific forms of emotions, such as anger, depression, or happiness that a person is experiencing.

In this article we make an attempt to explore the verbal expression of emotions, the language-emotion relationship. Verbal expression of emotions refers to the manifestation of emotions through language. Valuable insights about the verbal expression of emotions have come from investigators in a number of fields, including linguistics, sociolinguistics, psycholinguistics, anthropological linguistics and psychology. 
All languages provide speakers with an array of verbal strategies to convey emotions. In English, for example, there is an abundance of both literal (e.g., sad, irked, angry, furious), and figurative (e.g., flipping one's lid, blow a gasket) expressions which can be used to describe a theoretically infinite number of emotional states. The relationship between language and emotions can be viewed from different angles. First, language, in a broad sense, can be viewed as being done "emotive". Taking this angle, it is commonly assumed that people "have" emotions, and that "being emotional" gains its own agency, impacting in a variety of ways on the communicative situation. As it was already mentioned, this can take place extralinguistically (e.g. by facial expressions, body postures, proximity, and the like), in terms of suprasegmentational and prosodic features, and in terms of linguistic (lexical and syntactic) forms. The "expression" of emotions, i.e. the behavioral act of expressing emotions in communication, relies heavily on the notions of what emotions are and how they function in private and public settings. Language and emotion are two concurrent, parallel systems in use, and their relationship exists in that one system (emotions) impacts on the performance of the other (language). Both of them share their functionality in the communicative process between people. The other tack on the relationship between language and emotion starts from the assumption that language in a way refers to, and therefore "reflects" objects in the world, among them the emotions, hence, languages have emotion terms, and people across the world use them in verbal interactions. In this view emotions are 'real' objects such as behaviors or they are 'internal' psychological states or processes resembling other psychological processes such as thoughts or intentions. This view then takes a different tack to the language-emotion relationship. Language is a means of making sense of emotions, and as such can be used as a starting point to explore the world of emotions in different languages. If language is conceived of as merely representing the world of emotions or people's conceptualizations and understandings of the emotions, language offers an immediate access. Language, in this view, is "transparent". We may conclude that if language is conceived of in one or another way as contributing to how emotions are understood, or what emotions "are", the relationship is not direct, but mediated.

The theoretical approaches presented by different researchers, which we discuss in this article, in some way, lead to an illumination of what is involved in the interplay of language, emotions, concepts of emotions.

In numerous articles and books Wierzbicka has explicated her theoretical view on how to analyze emotions. Emotions to her are a semantic domain to be investigated in a semantic metalanguage, i.e. in terms of indefinables or primitives, that is, semantic universals that are shared by all human languages. These universals are of a conceptual nature and comprise elements such as feel, want, say, think, know, good, bad, and so on. It is Wierzbicka's declared aim "to explore human emotions from a universal, languageindependent perspective". In her comparative study of language-dependent conceptualizations, Wierzbicka documents that "every language imposes its own classification upon human emotional experiences, and English words such as anger or sadness are cultural artifacts of the English language, not culture-free analytical tools" (1995:235). Her analyses are clear examples for exactly this point, and her main argument is forcefully 
directed against the psychological theorizing that starts from the assumption that emotions are bodily experienced feeling states, each categorically distinct, and built up in a clearly ordered sequence of events. (Sarbin 1995) In the following examples of the semantic explications of the abstract concept "GUILT" and the concrete concept "SKY" all the terms mentioned in combination are supposed to be universals and parts of what has been termed the "Natural Semantic Metalanguage" (NSM):

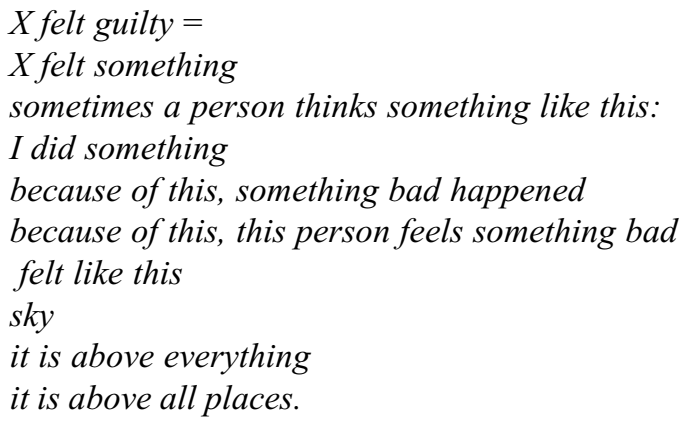

While the above explications resemble previous explications of situated and culturally shared meanings, it needs to be stressed that the explications within the NSM-framework are argued to operate from a non-contextual, culture free starting point. Within the framework chosen by Wierzbicka, language obviously plays a very important role to explore emotions, since her system of universals is labelled 'semantic primitives', which in their very nature are considered conceptual, cognitive.

Harré's suggestion that researchers study "the way people use their emotion vocabulary, in commenting upon, describing, and reprimanding people for emotional displays and feelings" (Harré \& Gillett 1994:148), is in many ways similar to Wierzbicka's approach. In aiming to conceive the uses of the emotional vocabulary of a given culture at a given time, Harré and Gillett offer the theory of "emotionology" or the "theory of emotion". In contrast to the universal orientation of Wierzbicka, an emotionology is a very local theory, which is said to consist of four general features. These features need close attention if an emotion is to be identified and labeled correctly: (1) a felt bodily disturbance, (2) a characteristic display, (3) the expression of a judgment, and (4) a particular illocutionary force. (Harré \& Gillett 1994) In keeping with the anthropological, cultural model approaches, Harré's emotionology adds the directive, cultural force of emotions to the representational system, i.e. the information about structure of experience or shared knowledge. This opens up space for investigations of the processes through which cultural knowledge obtains motivational force for individuals. According to Harré, cultural meanings are potentially conflicting and more loosely organized. At the same time, Harré views emotions (as all other psychological processes) as products of discourse, constituted in interaction (Harré \& Gillett 1994), hence he puts a new emphasis on the study of emotions which is more thoroughly discourse oriented. 
It should be mentioned that Harré's suggestion to study emotion terms as part of a lexicon sounds very much like Wierzbicka's study of word reference (Wierzbicka 1995), but he also offers to study the emotion vocabulary of a certain group of people. If references to emotions - in the realm of texts - position people with regard to one another (morally, aesthetically), they function as indexes to how emotions in discourse situations are displayed, that is, what emotions mean as discursive acts. Thus, employing emotionologies for the study of emotions as discursive acts orients us toward the study of language use in discourse situations. In coining the term "emotional styles", Harré draws attention to the study of culture, though not by venturing into general hypotheses about universal functions and characteristics of emotions. He claims that culture means "gaining a comparative sense - how the emotion in question is different from one case to the next - even if the end result is primarily to understand one particular cultural expression..." (Harré \& Gillett 1994).

An interesting point for venturing into the acquisition of emotions is admitted by Lutz. With anthropological approaches to emotions, he puts an emphasis on the cognitive and conceptual aspects of emotions (Lutz \& White, 1986). In an apparent parallel with Wierzbicka, Lutz claims that "emotion can be viewed as a cultural and interpersonal process of naming, justifying, and persuading by people in relationship to each other" (Lutz 1986). However, the anthropology of emotions does not seem to claim psychological reality for the kind of conceptual analysis that is employed in the process of explicating the experiential, expressive, and regulative aspects of emotion displays. In taking the work of Catherine Lutz on the Ifaluk emotionology as an example, Harré and Gillett document that emotion words function to fashion - so to speak - emotional acts. (Harré \& Gillett 1994) This is not meant to imply that emotionologies are the same as emotion display systems; but describing a person as angry, or in terms of the Ifaluk as doing metagu ('behaving inappropriately'), passes a judgment on the person talked about, and implicates this person with regard to the performance of a particular illocutionary act. Thus, emotion words do the job of orienting toward a particular "positioning" within social encounters.

In a number of publications, Nancy Stein and her associates have been investigating the cognitive capacity of simulating the plans and goals relevant to the understanding of human actions as part of the study of personal and social behavior (Stein 1992). Stein's original research in children's understanding of human intentionality in their story constructs has moved focus more strongly on the appraisal processes relevant to assessing the specific goals, values, and moral principles involved in the understanding of characters' actions. And since the knowledge about valued goals and their outcomes is taken to be heavily influential on how characters 'feel' and how they consequentially react, a model has emerged that is argued to capture the "meaning of emotions", i.e. it can spell out the appraisal processes that link the occurrence of a situation to an emotion and delineate the nature and boundaries between emotions (Stein 1992). According to Stein and her associates, if emotions are approached as a representational system of some specific goal-planoutcome knowledge, then the acquisition of categorical distinctions between the basic as well as culture-specific emotions consists in its most basic form of knowledge of inten- 
tional action and of goal plans. In Stein's approach, these two knowledge types are acquired relatively early, at around three years of age. At this point, children can successfully differentiate the components that lead to (English) anger, sadness, fear, and happiness, and many efforts have been made on illustrating how children make use of this knowledge in later years in other problem solving tasks (Stein 1992). Using narratives of real life emotional situations and subjecting them to on-line questions for on-line reasoning, Stein and her colleagues rely on language in its ideational, representational function, as a relatively transparent window to what the narrator means when talking about emotions. The content of the topic is taken as what is of basic concern, and whether the narrator wants to be understood as blaming another person or saving face, i.e. the directive force of language use is not considered of immediate relevance (Stein 1979). Similarly, the directive force of culture in the form of rules and norms for conduct becomes relevant as a 'secondary' force, i.e. by way of individually represented cognitive systems, containing information about individual experiences and culturally shared knowledge.

\section{Conclusion}

Thus, each of the represented approaches offers unique insights into verbal expression of emotions and language-emotion correlations. Wierzbicka views emotions as a semantic, conceptual domain which governs the patterns of discourse, Harré takes emotions to be a part of the domain of statements, actions and interactions, meanwhile, Stein's approach to emotions seems to combine aspects of both: emotions are schematically organized, i.e. part of a representational system, and these schemata are 'put to work', namely, expressed verbally as a response to emotional events. The verbally expressed emotions are first of all cognitions. They force the individuals to react in a certain manner. Hence, the verbal descriptions of emotional states are able to provide quite precise information about the specific forms of emotions the person is experiencing.

"This is the greatest paradox: the emotions cannot be trusted; yet it is the emotions that tell us the greatest truths."

Don Herold

\section{References:}

1. Harré, R. (1986) The Social Construction of Emotions. Oxford, England: Basil Blackwell.

2. Lutz, C. \& White, G.M. (1986). The Anthropology of Emotions. Annual Review of Anthropology. Chicago: Chicago University Press.

3. Sarbin, T.R. (1995) Emotional Life, Rhetoric, and Roles. // Journal of Narrative and Life History. NY: New York University Press.

4. Stein, N.L. \& Trabasso, T. (1992) The Organization of Emotional Experience: Creating Links Among Emotion, Thinking and Intentional Action. American Educational Research Association, San Francisco, CA. 
5. Stein, N.L. (1979) The Concept of a Story: A Developmental Psycholinguistic Analysis. American Educational Research Association, San Francisco, CA.

6. Wierzbicka, A. (1995) Emotion, Language, and Cultural Scripts, Emotion and Culture. Washington, DC: American Psychological Association.

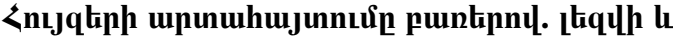 hnıjqtiph unfuuqnhgnıpjnıfifitpn}

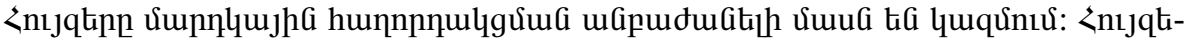

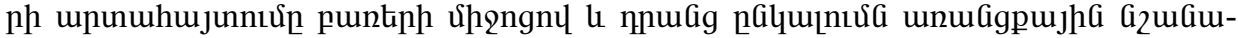

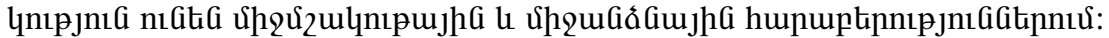

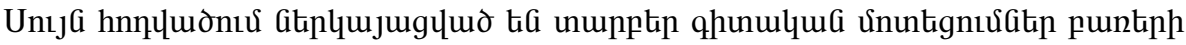

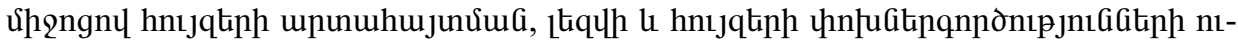
unıরiGuuhnnıpjug umuhG:

\section{Вербальное выражение эмоций: взаимодействие языка и эмоций}

Эмоции являются неотьемлемой частью человеческой коммуникации. Вербальная экспрессия эмоций и их правильное восприятие имеет ключевое значение в межкультурных и межличностных отношениях.

В данной статье представлены разные теоретические подходы к исследованию вербальных эмоций, о взаимодействии человеческого языка и эмоций. 